\title{
Monitoring breath carbon monoxide gas using micro thermoelectric sensor
}

\author{
D. Nagai ${ }^{1}$, T. Nakashima ${ }^{1}$, M. Nishibori ${ }^{1}$, T. Itoh ${ }^{1}$, N. Izu ${ }^{1}$, W. Shin ${ }^{1}$ \\ ${ }^{1}$ National Institute of Advanced Industrial Science and Technology (AIST), 2266-98 Anagahora, \\ Shimo-Shidami, Moriyama-ku, Nagoya, 463-8560 Japan \\ ${ }^{2}$ Research Center for Synchrotron Light Applications Kyushu University, 6-1 Kasuga-koen Kasuga- \\ city, Fukuoka, 816-8580 Japan
}

\begin{abstract}
:
The CO gas, which is several ppm level in the human breath, is used for medical examination. In this study, $\mathrm{CO}$ combustion catalysts of $\mathrm{Au}, \mathrm{Pt}$ and $\mathrm{Pd}$ loaded on $\mathrm{CoO}$ on the thermoelectric gas sensor (TGS) were developed and the combustion performance of these catalysts was evaluated. We have demonstrated that the micro-THS detected the $\mathrm{CO}$ concentration in air from low as $1 \mathrm{ppm}$ to high as 1 $\mathrm{vol} \%$. The noise voltage level of the sensor was $0.13 \mu \mathrm{V}$, and the signal to noise ratio, $\mathrm{S} / \mathrm{N}$ was $2.09 \mu \mathrm{V} / 0.13 \mu \mathrm{V}=16.1$ for $1 \mathrm{ppm} \mathrm{CO} /$ air.
\end{abstract}

Key words: Catalyst, Combustion, Thermoelectric device, Carbon monoxide

\section{Introduction}

The inflammable gas, $\mathrm{CO}, \mathrm{CH}_{4}$ and $\mathrm{H}_{2}$, which are several to hundreds ppm in human breath can be used for medical examination and be detected by the micro thermoelectric gas sensor (TGS) with the combustion catalyst. A micro-TGS can be useful platform device, because it is possible to modify the catalyst of the micro-TGS for the target gas. We have reported that the micro-TGS with Pt-loaded alumina (40wt\%Pt/alumina) catalyst could detect hydrogen $\left(\mathrm{H}_{2}\right)$ gas for wide concentration range from extremely low $\mathrm{s} 0.5 \mathrm{ppm}$, up to high as 5 vol. $\% \mathrm{H}_{2}$ in air, and showed a good linearity between the $\mathrm{H}_{2}$ concentration in air and the sensing signal at the catalyst temperature of $100{ }^{\circ} \mathrm{C}$ [1]. We have succeeded to measure the $\mathrm{H}_{2}$ in breath in ppm level [2].

The carbon monoxide (CO) is a inflammable gas that can be formed endogenously and is detectable in exhaled breath in the level of sevral ppm. The origin of breath $\mathrm{CO}$ are considered to be the enzymatic degradation of haem, non-haem-related release and exogenous $\mathrm{CO}$. Though the cigarette smoke seriously affect the $\mathrm{CO}$ level of breath, $\mathrm{CO}$ can be used as a promising marker to assess many diseases, such as asthma, COPD, CF and other lung disease [3]. The use of TGS for CO detection has been demonstrated by integrating $\mathrm{CO}$ combustion catalyst of $\mathrm{Au} / \mathrm{TiO}_{2}$ on the
micro-TGS [4]. We have prepared a $20 \mathrm{wt} \%$ $\mathrm{Au} / \mathrm{TiO}_{2}$ catalyst and evaluated the combustion performance of this catalyst on the micro-TGS. The combustion performance of the 20 wt $\% \mathrm{Au} / \mathrm{Co}_{3} \mathrm{O}_{4}$ catalyst was still low, the lower limit detection is the $250 \mathrm{ppm}$. It is difficult to measure $\mathrm{CO}$ concentration in human breath. We have investigated the new catalyst of $\mathrm{Au} / \mathrm{CO}_{3} \mathrm{O}_{4}$ [4] by changing $\mathrm{TiO}_{2}$ to $\mathrm{Co}_{3} \mathrm{O}_{4}$ and AuPdPt $/ \mathrm{CO}_{3} \mathrm{O}_{4}[5]$ by adding $\mathrm{Pd}$ and $\mathrm{Pt}$ to improve the catalyst performance of the TGS for $\mathrm{CO}$ gas so that, this catalyst system could be applied for the application of breath $\mathrm{CO}$ monitoring where $\mathrm{CO}$ and $\mathrm{H}_{2}$ coexist in ppm level.

In this study we have investigated the performance in low $\mathrm{CO}$ concentration (ppm level) of TGS with AuPdPt/CoO, and the CO concentration in the human breath was evaluated by the TGS.

\section{Experiment}

Figure 1 (a) shows the optical image of the micro-TGS with ceramic combustion catalyst. A double-side polished Si with $0.35 \mathrm{~mm}$ thickness was used as a substrate. Sillicon-germanium (SiGe) was deposited by DC magnetron sputtering and patterned into thermoelectric (TE) material by RIE etching. Micro-heater and electrode lines were fabricated by a lift off technique using platinum. To fabricate a membrane structure, the reverse side of the 
substrate was etched out by using $\mathrm{KOH}$ aqueous solution. The detail process has been reported previously [1]. The AuPtPd/CoO catalyst powder was prepared by colloid of cobalt support. The content of every metal element was $1 \mathrm{wt} \%$. The ceramic paste of the catalyst was prepared by mixing terpineol, ethyl cellulose and distillated water with the weight ratio of $9: 1: 5$.

A drop of the ceramic paste was deposited on the thin membrane of the micro-TGS by an air dispenser. The size of the drop on the membrane could be controlled to $0.8 \mathrm{~mm}$ in diameter by changing the dispensing time and pressure. After the paste deposition, the device was baked in air at $300{ }^{\circ} \mathrm{C}$ for $2 \mathrm{~h}$. The gas responses of the sensor were investigated by a flow type chamber, and the $\mathrm{CO}$ concentration in the human breath was evaluated by the microTGS.

\section{Results and discussion}

The operating temperature of the sensor device is defined to the surface temperature of the catalyst center, which was controlled by the microheater. Both temperatures of the hot-side, the center of catalyst, and the cold-side junction were monitored by an IR camera as shown in Fig. 1 (b).

(a)

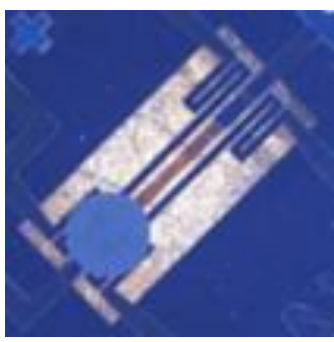

(b)

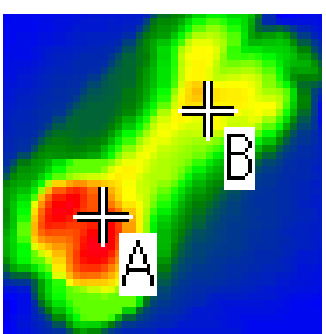

Figure 1: (a) The optical image of the ceramic combustion catalyst and the heater pattern on the thin membrane of micro thermoelectric gas sensor (b) IR image of the micro-TGS. The micro-TGS converts the $\Delta T_{A-B}$ into the thermoelectric voltage signal $\Delta V_{S}$

Figure 2 shows the voltage signals $\Delta V_{S}$ and temperature difference $\Delta T_{A-B}$ of the micro-TGS at operating temperature of $200^{\circ} \mathrm{C}$. The microTGS converts the temperature difference between hot and cold side, $A$ and $B$, into voltage signal by the Seebeck effect, $\Delta V_{S}=\alpha \Delta T_{A-B}$, where is $\alpha$ is Seebeck coefficient. The apparent Seebeck coefficient $\alpha_{\text {app }}$ of the SiGe film on the TGS device was not changed with the gas concentration, and estimated to be $0.30 \mathrm{mV} / \mathrm{K}$ in average, from the data of signal levels and the temperature differentials plotted in Fig.2.
The combustion performance of the catalyst is strongly dependent on the temperature. The catalytic combustion type sensor should be used over the light off temperature of the catalyst, i.e. saturated performance of the oxidation reaction is essential for the reliable output signal and linearity of the sensors.

(a)

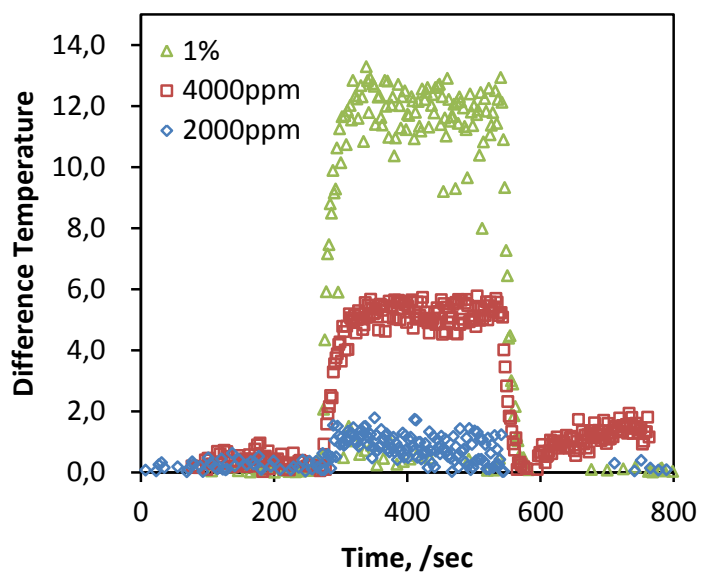

(b)

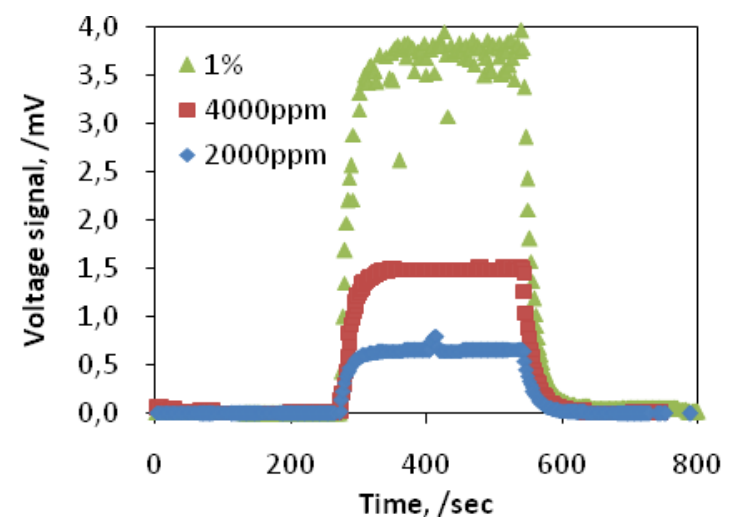

Figure 2: The property of the micro-TGS with ceramic combustion catalyst AuPtPd/CoO (a) The voltage signals $\Delta V_{S}$ of the micro-TGS at operating temperature of $200^{\circ} \mathrm{C}$ (b) and temperature difference $\Delta T_{A-B}$

The sensor performance, the voltage signals $\Delta V_{S}$, with different catalyst temperature from $50^{\circ} \mathrm{C}$ to $250^{\circ} \mathrm{C}$ have been investigated as shown in Fig. 3. If the activity of the combustion catalyst saturated with temperature change, then the $\Delta V_{S}$ become unchanged, and the catalytic combustion is proportional to the inflammable gas concentration [1].

Figure 3 shows the temperature dependence of the voltage signal $\Delta V_{S}$ of the sensor for the $2000 \mathrm{ppm}$ CO/air mixture gas and the combustion performance of the micro-TGS with AuPtPd/CoO catalyst activated from the temperature of $150^{\circ} \mathrm{C}$. The signal increased up 
sharply with temperature around $150^{\circ} \mathrm{C}$ and saturated over $250^{\circ} \mathrm{C}$. Considering the gas selectivity, the catalyst temperature of the $\mathrm{CO}$ sensor was set to $200^{\circ} \mathrm{C}$.

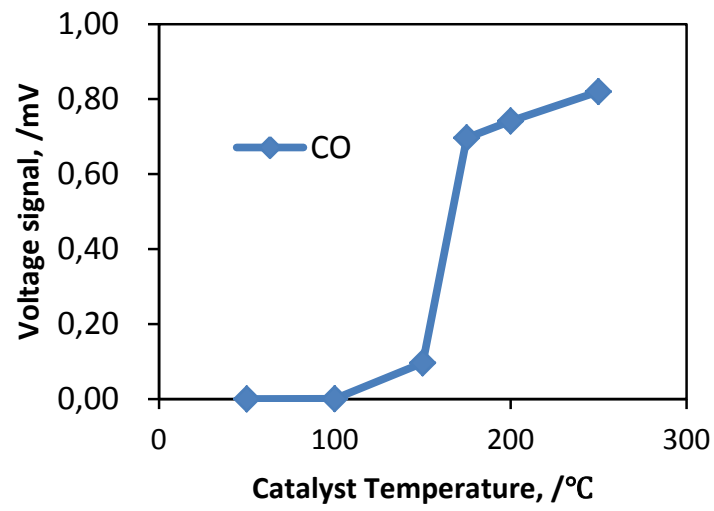

Figure 3: The voltage signals $\Delta V_{S}$ at operating temperature of from $50^{\circ} \mathrm{C}$ to $250^{\circ} \mathrm{C}$

Figure 4 shows the voltage signals $\Delta V_{S}$ of the CO/air mixture gas from 1 to $1000 \mathrm{ppm} \mathrm{CO}$ concentration. The TGS sensor showed a very linear relationship between voltage signal and CO concentration for wide range. For the detected lowest concentration $1 \mathrm{ppm} \mathrm{CO} /$ air, the voltage signal was approximately $2.09 \mu \mathrm{V}$ and the temperature difference $\Delta T_{A-B}$ was calculated to be $0.0070{ }^{\circ} \mathrm{C}$ by Seebeck coefficient $\alpha_{\text {app }}=$ $0.30 \mathrm{mV} / \mathrm{K}$ obtained by above discussion. The noise voltage level of this sensor was $0.13 \mu \mathrm{V}$, and the signal to noise ratio, $S / N$ was $2.09 \mu \mathrm{V} / 0.13 \mu \mathrm{V}=16.1$ for $1 \mathrm{ppm} \mathrm{CO} /$ air.

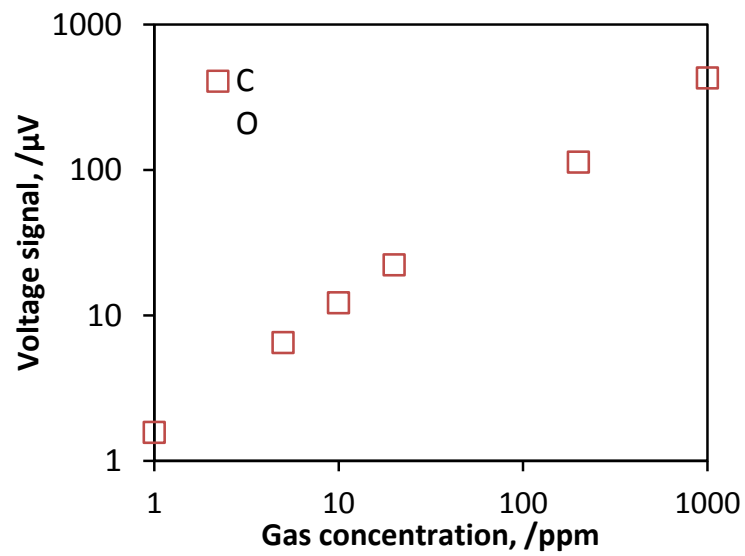

Figure 4: The relationship between voltage signals $\Delta V_{S}$ and $C O$ concentration.

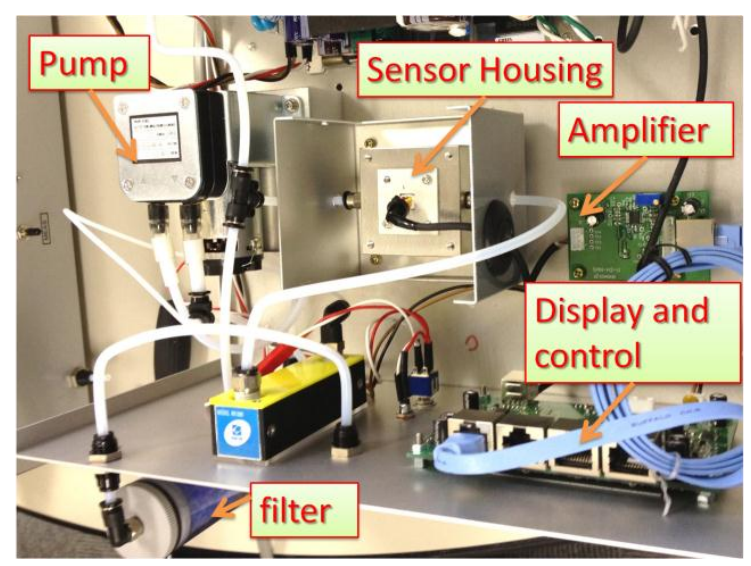

Figure 5: Prototype breath gas monitoring system for $C O$ gas.

Figure 5. shows the inside view of the prototype system. The breath gas is feeded by the air pump and flow into the sensor housing by passing the filter. The CO TGS sensor was integrated into a metal chamber to reduce the noise of the thermal fluctuations. The major interference gas in breath is hydrogen, and the CO gas selectivity of the CO TGS sensor has been investigated with this system.

\section{Acknowledgement}

This work was supported by the project "Development Project for Extremely-Early Diagnostics Technologies for Human Diseases" of Aichi prefecture, Japan.

\section{References}

[1] M. Nishibori, W.Shin, Lionel F. Houlet, K. Tajima, T. Itoh, N. Izu, N. Murayama and I. Matsubara, "New Structural Design of Micro-Thermoelectric Sensor for Wide Range Hydrogen Detection", J. Ceram. Soc. Japan. 114 [10] (2006) 853-856.

[2] W. Shin, M. Nishibori, N. Izu, T. Itoh, I. Matsubara K. Nose and A. Shimouchi, "Monitoring Breath Hydrogen Using Thermo", Sensor Lett. 9, (2011) 684-687

[3] S. A. Kharitonov and P. J. Barnes, "Biomakers of some pulmonary diseases in exhaled breath ", Biomakers 7 (2002) 1-32.

[4] M. Nishibori, K. Tajima, W. Shin, N. Izu, T. Itoh and I. Matsubara, "CO oxidation catalyst of AuTiO2 on the thermoelectric gas sensor", J. Ceram. Soc. Japan 115 (1) (2007)34-41

[5] N. Nishibori, W. Shin, N. Izu, T. Itoh, I. Matsubara, "CO combustion catalyst for micro gas sensor application", JOURNAL OF MATERIALS SCIENCE, 46, (2011)1176-1183

[6] M. Nishibori, T. Nakashima, T. Itoh, N. Izu, W. Shin, 24th Fall Meeting of the Ceramic Society of Japan, Hokkaido, Japan, (2011)170 